\title{
Aplicabilidade dos limites da velocidade do ar para efeito de conforto térmico em climas quentes e úmidos
}

\author{
The relevance of air velocity limits for thermal comfort
} purposes in hot-humid climates

\section{Christhina Candido \\ Roberto Lamberts \\ Leonardo Bittencourt \\ Richard de Dear}

\section{Resumo}

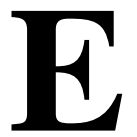

ste trabalho discute os limites dados para a velocidade do ar pelas normas ASHRAE 55 (2004) e ISO 7730 (2005). Para tal, realizou-se uma análise comparativa entre os valores-limite para a velocidade do ar definidos por essas normas e as respostas dos usuários em relação à

Christhina Candido Faculty of Architecture, Design and Planning University of Sydney Sydney - Australia NSW, 2006

Tel.: (612) 9351-3206 E-mail: chrismcandido@yahoo.com

Roberto Lamberts Centro Tecnológico, Departamento de Engenharia Civil Universidade Federal de Santa Catarina Campus Universitário, Trindade, Caixa Postal 476 Florianópolis - SC - Brasil CEP 88040-900 Tel.: (48) 3721-7090 E-mail: lamberts@ecv.ufsc.br

Leonardo Bittencourt

Centro de Tecnologia, Departamento de Arquitetura e Urbanismo Universidade Federal de Alagoas Campus A. C. Simões, BR 104 Norte, KM 97, Cidade Universitária Maceió - Al - Brasil CEP 57072-970

Tel.: (82) 3214-1290

E-mail: Isb54@hotmail.com

Richard de Dear Faculty of Architecture, Design and Planning

University of Sydney

Sydney - Australia NSW, 2006

Tel.: (612) 9351-2801

E-mail: r.dedear@usyd.edu.au

Recebido em 20/02/10

Aceito em 14/08/10 preferência e aceitabilidade do movimento do ar obtidas em experimentos de campo realizados em Maceió/AL. Resultados indicam que ambas as normas especificam valores para a velocidade do ar inferiores aos desejados pelos usuários. Os resultados da preferência do movimento do ar indicam que significativa percentagem dos usuários demanda "maior movimento do ar". Quando associada às respostas da aceitabilidade do movimento do ar, a insatisfação dos usuários ficou mais evidente, assim como a demanda por maior velocidade do ar. O mesmo movimento de ar, considerado como inaceitável em climas frios e temperados, é desejado pelos usuários em climas úmidos. Nesse contexto, a aplicabilidade de limites máximos para a velocidade do ar provenientes de estudos com características climáticas diferentes deve ser evitada. Tais limites devem vir de resultados de experimentos de campo em ambientes naturalmente ventilados, onde os usuários possam utilizar de oportunidades adaptativas para reestabelecer o conforto térmico. Futuras normas brasileiras devem focar em tais questões, visando limites de velocidade que correspondam à expectativa dos usuários em climas quentes e úmidos.

Palavras-chave: Velocidade do ar. Conforto térmico. Normas.

\section{Abstract}

This article discusses the air velocity limits established by ASHRAE 55 (2004) and ISO 7730 (2005). A comparative analysis was developed between those air velocity limits and users' answers for air movement preferences and acceptability, obtained in field experiments carried out in the city of Maceio, Alagoas, Brazil. The results suggest that the air velocity limits specified by those standards are lower than those required by users. The results indicate that a significant percentage of users demand "more air movement". When those results were combined with the answers on air movement acceptability, the number of unsatisfied users increased, as well as the demand for higher air velocity levels.

The same air movement that is considered unacceptable in cold or temperate climates is desirable in hot-humid climates. Therefore the application of maximum air velocity limits from studies carried out in a climate that has different characteristics should be avoided. Air velocity limits should be defined based on field experiments in naturally ventilated indoor environments where adaptive opportunities are available in order to re-establish users' thermal comfort. Future standards in Brazil should consider these issues, in order to establish air velocity limits that can meet users expectations in hot-humid climates.

Keywords: Air velocity. Thermal comfort. Standards. 


\section{Introdução}

Um dos principais argumentos associados aos limites máximos para a velocidade do ar em ambientes internos advém do conceito de que desconforto pode ocorrer pelo incremento do movimento do ar, ou o chamado desconforto por correntes de ar (i.e. draft). A intensidade de tal fenômeno é intrinsecamente relacionada à combinação da temperatura e da velocidade do ar e também a fatores complementares, tais como a intensidade de turbulência e a área do corpo do usuário exposta (MCINTYRE, 1978). Tais constatações advêm de experimentos realizados em câmaras climáticas, com usuários desenvolvendo atividades sedentárias, utilizando vestimenta leve e sem oportunidades adaptativas (FANGER; PEDERSEN, 1977; FANGER; CHRISTENSEN, 1986).

A equação resultante é utilizada para estimar o percentual de usuários insatisfeitos com o movimento de ar e serve como referência para os limites considerados como máximos para a ASHRAE 55 (2004) e ISO 7730 (2005). A Equação 1 mostra as variáveis utilizadas para tal cálculo. O percentual de insatisfação dos usuários preditos pela Equação 1 é válido para condições cuja temperatura do ar varia entre $20^{\circ} \mathrm{C}$ e $26^{\circ} \mathrm{C}$, com velocidade média entre 0,05 e $0,40 \mathrm{~m} / \mathrm{s}$ e intensidade da turbulência inferior a $70 \%$. A aplicabilidade de tais valores é estritamente limitada às condições laboratoriais onde foram encontrados (ambientes com ar-condicionado) e/ou climas com características semelhantes.

$$
D R=\left(34-t_{a}\right) \times(\bar{v}-0.05)^{0.62} \times(0.37 \times \bar{v} \times T u+3.14)(\%) \quad \text { Eq. } 1 .
$$

Onde:

DR = percentual de usuários sentindo desconforto causado pelo movimento do ar;

$\bar{v}=$ velocidade média do ar $[\mathrm{m} / \mathrm{s}]$;

$t_{a}=$ temperatura do ar $\left[{ }^{\circ} \mathrm{C}\right] ; \mathrm{e}$

$T u$ = intensidade de turbulência [\%].

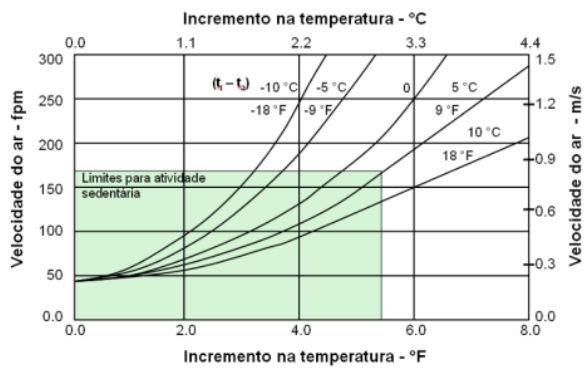

(a)
Normas internacionais oferecem, além da Equação 1 , gráficos complementares para se obterem os valores de velocidade do ar nos ambientes internos. Na ASHRAE 55 (2004), os limites para a velocidade do ar podem ser obtidos de duas formas. A primeira utiliza a Equação 1 como referência, sendo aplicável para os ambientes de forma geral. A norma ainda considera o desconforto por correntes de ar como um dos itens relacionados ao desconforto térmico localizado, que, por sua vez, também é relacionado à determinação das condições de aceitabilidade térmica do ambiente. De acordo com esse item, o valor máximo de usuários insatisfeitos devido ao desconforto provocado por correntes deverá ser de $20 \%$.

A segunda forma de obtenção dos valores máximos para a velocidade do ar é tratada especificamente para os casos cujo incremento do movimento do ar é desejado e quando os usuários têm o controle dos mecanismos de ventilação. Nesse caso, o valor máximo pode ser obtido pelo cruzamento dos valores do incremento da temperatura do ar com os valores da diferença entre a temperatura radiante e a temperatura do ar, conforme a Figura 1a. Apesar de a escala apresentar valores entre 0 e $1,50 \mathrm{~m} / \mathrm{s}$, a norma explicita claramente que a velocidade não deverá exceder $0,80 \mathrm{~m} / \mathrm{s}$ e que o ajuste permitido aos usuários não deve ser superior a $0,15 \mathrm{~m} / \mathrm{s}$.

Na ISO 7730 (2005), os valores máximos para a velocidade do ar também se baseiam na Equação 1. De forma complementar, essa norma apresenta o gráfico da Figura 1b, que informa o limite da velocidade do ar em função dos valores da temperatura do ar e da intensidade de turbulência. Como resultado, pode-se obter valores para um máximo de $15 \%$ de insatisfação dos usuários. Os valores da velocidade do ar variam entre 0 e 0,40 $\mathrm{m} / \mathrm{s}$, para temperaturas do ar entre $18{ }^{\circ} \mathrm{C}$ e $26^{\circ} \mathrm{C}$ e turbulência oscilando entre $0 \%$ e $60 \%$ (Figura 1b).

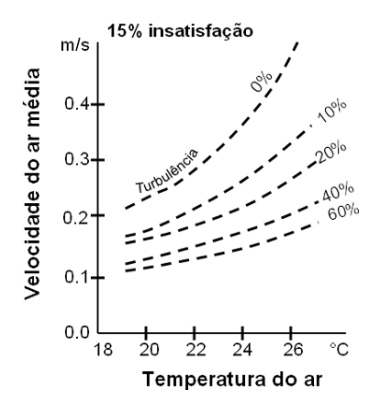

(b)

Figura 1 - Determinação dos valores da velocidade do ar de acordo com a (a) ASHRAE 55 (2004) e (b) ISO 7730 (2005), livremente adaptados e traduzidos dos originais 
Em climas quentes, ou moderadamente quentes, no entanto, o mesmo movimento do ar que é considerado como desconfortável em climas frios e temperados, pode ser tido como extremamente bem-vindo pelos usuários para fins de conforto térmico. A aplicabilidade de limites máximos para a velocidade do ar advindos de experimentos laboratoriais vem sendo cada vez mais questionada, principalmente quando se trata de ambientes reais, com usuários utilizando oportunidades adaptativas (ARENS et al., 1998, YANG; ZHANG, 2008; ZHANG et al., 2007a). Do ponto de vista fisiológico, o mesmo incremento do movimento do ar em climas frios e em climas quentes é percebido de maneira diferente pelos usuários, podendo o mesmo insuflamento de ar ser considerado uma incômoda corrente de ar ou uma agradável brisa. Tal percepção pode ser explicada fisiologicamente pelo fato de os termorreceptores para frio estarem localizados mais superficialmente na pele que os de calor (DEAR, 2009). Nessa abordagem, a diferença na percepção do mesmo movimento do ar pode ser explicada pelo conceito de alliesthesia (CABANAC, 1971). Segundo esse conceito, o estímulo causado no ambiente pode ser positivo ou negativo, dependendo de como ele auxilia ou dificulta o restabelecimento (alliesthesia positiva) ou afastamento (alliesthesia negativa) do conforto do usuário (DEAR, 2009). Dessa forma, os ambientes que utilizam a ventilação natural como estratégia de condicionamento oferecem esse estímulo positivo, e as flutuações do movimento e velocidade do ar podem ser não só bem-aceitas, mas até desejadas pelos usuários.

Resultados de uma ampla análise realizada no banco de dados do RP-884 da ASHRAE mostram que, do ponto de vista de preferência e expectativa, em ambientes onde a ventilação natural é utilizada como a principal forma de condicionamento os usuários tendem a indicar frequentemente preferência por "maior movimento do ar" (ZHANG et al., 2007b). Nesse banco de dados, a velocidade média foi de $0,30 \mathrm{~m} / \mathrm{s}$, estando, portanto, dentro dos limites utilizados na ASHRAE 55, por exemplo. Com base em tais evidências, Arens et al. (2009) sugerem uma revisão dos valores de velocidade do ar permitidos em ambientes internos da ASHRAE 55 (2004). Tal proposta amplia os limites máximos da velocidade do ar, de acordo com o tipo de controle dos usuários em relação a janelas e ventiladores. De acordo com os autores, é possível ampliar a velocidade do ar de $0,80 \mathrm{~m} / \mathrm{s}$ para até $1,20 \mathrm{~m} / \mathrm{s}$, se o controle local estiver disponível para grupos de até 6 usuários. Tais limites são, sem dúvida, um avanço em estimular o uso de valores mais elevados para a velocidade do ar.

É sabido que a extrapolação e o uso de limites para velocidade do ar oriundos de estudos com realidades climáticas diferentes podem resultar em significativa disparidade em termos de aceitabilidade térmica em geral e em preferência do movimento do ar. No entanto, pouco foi desenvolvido no intuito de se aprofundar o entendimento de aspectos subjetivos da relação do usuário com a intensidade do movimento do ar. Nesse sentido, estudos que comparam tais valores máximos da velocidade do ar com os resultados da preferência e aceitabilidade do movimento de ar dos usuários se constituem em importante contribuição para essa área do conhecimento. Este trabalho sugere analisar os usuários em termos de aceitabilidade do movimento do ar e tem como objetivo comparar os limites estabelecidos para a velocidade do ar, pelas normas ASHRAE 55 (2004) e ISO 7730 (2005), com base em experimentos de campo realizados no clima quente e úmido de Maceió - AL.

\section{Método}

Este trabalho baseia-se numa análise comparativa entre os valores definidos como velocidade do ar pelas normas ASHRAE 55 e ISO 7730, com os resultados obtidos em experimentos de campo em relação à preferência e aceitabilidade do movimento do ar.

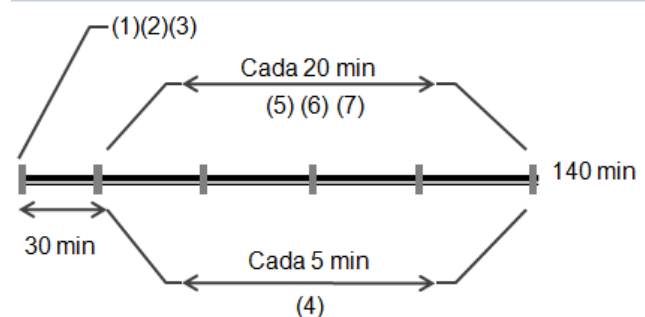

(4)
(1) Assentamento dos instrumentos de medição

(2) Registro das informações do ambiente

(3) Distribuição dos questionários e explicação detalhada do procedimento para os usuários

(4) Contínuo registro das variáveis ambientais

(5) Avaliação de conforto e aceitabilidade térmica e do movimento do ar

(6) Medições individualizadas da velocidade do ar

(7) Observação e registro do uso de oportunidades adaptativas

Figura 2 - Esquema do procedimento adotado para os experimentos de campo 
Os experimentos de campo ${ }^{1}$ foram desenvolvidos em salas de aula e ateliês de desenho do Curso de Arquitetura e Urbanismo da Universidade Federal de Alagoas e do Centro de Estudos Superiores de Maceió. Os ambientes utilizam a ventilação natural como estratégia principal de condicionamento térmico, sendo esta complementada pelo uso de ventiladores de teto. O estudo foi conduzido durante duas semanas, nos meses de verão e inverno, nos períodos da manhã, tarde e noite, resultando em 2.075 questionários respondidos pelos ocupantes de tais ambientes. Um esquema do procedimento adotado para tais experimentos pode ser visto na Figura 2.

A idade dos usuários variou entre 18 e 25 anos, e a maioria dos entrevistados foi do sexo feminino (cerca de 66\%). As atividades desenvolvidas foram sedentárias e variavam entre $70 \mathrm{~W} / \mathrm{m}^{2}$ e $93 \mathrm{~W} / \mathrm{m}^{2}$, visto que os usuários encontravam-se sentados escrevendo ou desenhando, ou desenhando em pé. A vestimenta utilizada foi, em média, leve, considerando-se os valores de 0,30 clo para o verão e de 0,70 clo para o inverno, conforme classificação da ASHRAE 55 (2004). As atividades dos alunos não foram interrompidas durante os experimentos, visando caracterizar a utilização real dos ambientes, incluídas as oportunidades adaptativas dos usuários. Da mesma forma, permitiu-se o uso de ventiladores de teto, acionamento de lâmpadas e controle das aberturas (fechar ou abrir portas e janelas) e ajustes desejados para as vestimentas.

As variáveis ambientais foram registradas com o confortímetro Babuc A, localizado no centro das salas. Tal instrumento serviu para registrar os valores da temperatura do ar, temperatura de globo, umidade e velocidade do ar do ambiente. Com base em tais valores, pode-se calcular as variáveis derivadas (temperatura operativa, temperatura radiante média, etc.). Sendo a velocidade do ar o foco central deste trabalho, ela foi registrada de forma individualizada $\mathrm{e}$ simultânea ao preenchimento dos questionários de aceitabilidade térmica e ambiental pelos usuários. Para tal, utilizou-se um termoanemômetro portátil e bastões de fumaça para o registro da velocidade do ar e direção predominante do fluxo de ar respectivamente. $\mathrm{O}$ controle de abertura de janelas e portas bem como o acionamento de ventiladores foram realizados livremente pelos usuários, sem nenhuma interferência dos pesquisadores. Tais mudanças foram registradas pelos pesquisadores, em separado, juntamente com a hora em que foram observadas, no formulário de controle de

\footnotetext{
${ }^{1}$ Mais detalhes sobre essa metodologia podem ser vistos em Cândido et al. (2010).
}

observação dos ambientes internos, servindo como indicação do uso efetivo das oportunidades adaptativas.

O questionário utilizado baseia-se no modelo de Dear e Brager $(2002)^{2}$ e foi adaptado para o desenvolvimento deste trabalho, de acordo com as necessidades específicas dele. O questionário de aceitabilidade térmica e ambiental inclui questões relativas ao conforto térmico dos usuários, aceitabilidade e preferência térmica, preferência e aceitabilidade do movimento do ar, assim como informações dos usuários (altura, idade, vestimenta, atividade). Os questionários foram associados com a posição específica do usuário no ambiente, no momento do preenchimento, facilitando a posterior análise individualizada dos resultados.

Todas as informações relacionadas ao experimento, tais como os ambientes, usuários, respostas dos usuários, variáveis ambientais, derivadas e calculadas, foram agrupadas em um banco de dados. Posterior tratamento estatístico aplicado foi desenvolvido com o software SAS @ , o que permitiu o refinamento das análises dos dados.

\section{Resultados}

A análise dos resultados foi dividida em duas partes. Primeiramente, encontraram-se os valores máximos para a velocidade do ar, de acordo com as normas, tendo como referência o gráfico da Figura 1a e 1b, apresentadas anteriormente. Tais resultados são apresentados na Tabela 1. Para viabilizar uma análise comparativa, os dados obtidos nos experimentos foram organizados de acordo com as especificações e limitações de cada norma para os valores das variáveis utilizadas, tais como temperatura do ar, temperatura operativa e intensidade de turbulência. Tendo com referência o gráfico da ASHRAE, os valores para a velocidade do ar variaram entre $0,30 \mathrm{~m} / \mathrm{s}$ e $1,20 \mathrm{~m} / \mathrm{s}$. No entanto, nessa norma, a velocidade de $0,80 \mathrm{~m} / \mathrm{s}$ é considerada como sendo o limite máximo aceitável. Por esse motivo, embora o valor de 1,20 $\mathrm{m} / \mathrm{s}$ conste do gráfico da Figura 1, o valor máximo adotado para a velocidade do ar foi de $0,80 \mathrm{~m} / \mathrm{s}$. Considerando as especificações da ISO 7730, os valores resultantes para a velocidade do ar variaram entre $0,15 \mathrm{~m} / \mathrm{s}$ e $0,20 \mathrm{~m} / \mathrm{s}$.

A segunda parte foi dedicada à análise das repostas dos usuários para preferência e aceitabilidade do ar, dentro dos valores máximos da velocidade que

${ }^{2} \mathrm{O}$ questionário se baseia no modelo utilizado por de Dear e Brager (2002), no desenvolvimento do projeto da ASHRAE RP 884 (Adaptive model). 
foram obtidos graficamente nas normas e sumarizados na Tabela 1. Essa análise é apresentada no capítulo a seguir.

\section{Preferência do movimento do ar}

A Figura 1a sumariza a distribuição de frequência para os resultados da preferência do movimento do ar, tendo como referência as especificações da ASHRAE. Os usuários classificaram a preferência do movimento do ar de acordo com três possíveis respostas: "maior movimento do ar", "assim mesmo" ou "menor movimento do ar". De forma geral, as respostas se concentraram nas opções "assim mesmo" e "maior movimento do ar".

Os resultados foram separados em duas categorias, dependendo do valor resultante da diferença entre a temperatura radiante e a do ar (Figura 1a). Quando essa diferença foi de $1{ }^{\circ} \mathrm{C}$, o percentual de usuários requisitando "maior movimento do ar" variou de $30 \%$ e $5 \%$ para velocidade do ar de 0,30 $\mathrm{m} / \mathrm{s}$ e $0,80 \mathrm{~m} / \mathrm{s}$ respectivamente. Nesse mesmo grupo $\left(\right.$ tr-ta $\left.=1{ }^{\circ} \mathrm{C}\right)$, a significativa maioria dos usuários indicou "assim mesmo" como preferência do movimento do ar, correspondendo a $68 \%, 69 \%$ e $83 \%$ para os respectivos valores da velocidade do ar $0,30 \mathrm{~m} / \mathrm{s}, 0,60 \mathrm{~m} / \mathrm{s}$ e $0,80 \mathrm{~m} / \mathrm{s}$.

Quando a diferença entre temperatura radiante e do ar foi anulada (tr-ta $=0{ }^{\circ} \mathrm{C}$ ), o percentual de usuários pedindo "maior movimento do ar" variou entre $68 \%$ e $42 \%$ para as velocidades de $0,30 \mathrm{~m} / \mathrm{s}$ e $0,80 \mathrm{~m} / \mathrm{s}$. Nesse caso, o percentual de usuários indicando "assim mesmo" como preferência para o movimento do ar aumentou em função do incremento da velocidade do ar, variando entre $22 \%$ e $58 \%$. Nota-se que o percentual máximo de usuários indicando preferência por "menor movimento do ar" foi significativamente inferior às outras duas opções, não ultrapassando $10 \%$ das respostas em todos os casos.

A Figura 3b sumariza os resultados para a preferência do movimento de ar tendo como referência a ISO 7730. Neste caso, os dados que delinearam a identificação dos valores da velocidade do ar incluem a temperatura do ar e a intensidade da turbulência $(\mathrm{Tu})$. Cruzando tais dados com os obtidos nos experimentos, a análise incluiu as ocorrências cuja temperatura do ar situava-se entre $24{ }^{\circ} \mathrm{C}$ e $26{ }^{\circ} \mathrm{C}$ e os valores da intensidade de turbulência de $40 \%$ e $60 \%$. Para a temperatura do ar de $24{ }^{\circ} \mathrm{C}$, o percentual de usuários demandando "maior movimento do ar" foi de $22 \%$ para turbulência de $40 \%$, e de $25 \%$ para turbulência de $60 \%$. No restante da amostra, os usuários indicaram "assim mesmo" como preferência do movimento do ar em $78 \%$ e $75 \%$ dos casos (para $\mathrm{Tu}=40 \%$ e $60 \%$ respectivamente). Para a temperatura do ar de $24{ }^{\circ} \mathrm{C}$, nota-se um incremento dos usuários demandando "maior movimento do ar" de $32 \%$ para $\mathrm{Tu}=40 \%$ e de $37 \%$ para $\mathrm{Tu}=60 \%$. Por outro lado, $12 \%$ dos usuários demandaram "menor movimento do ar" para $\mathrm{Tu}=40 \%$, e apenas $4 \%$ para $\mathrm{Tu}=60 \%$. Considerando a demanda por "menor movimento do ar" como usuários insatisfeitos por correntes de ar, o percentual foi significativamente inferior aos $20 \%$ indicados como valor máximo pela norma.

As duas normas especificam valores-referência para o percentual de insatisfação dos usuários relativo ao movimento do ar excessivo. A ASHRAE considera $20 \%$ como o valor máximo para a insatisfação dos usuários decorrente do excessivo movimento de ar (ou draft). Já na ISO 7730, o percentual de insatisfação dos usuários é inferior, de $15 \%$. Considerando-se os usuários que votaram por "maior movimento do ar" ou "menor movimento do ar" como insatisfeitos, nota-se que as normas definem velocidades do ar inferiores às desejadas pelos usuários. Ao analisar a distribuição das preferências do movimento do ar, observa-se que o maior percentual de insatisfação dos usuários foi relacionado à necessidade de maior movimento do ar e que os usuários demandando menor movimento do ar foram significativamente inferiores.

\begin{tabular}{|c|c|c|c|c|c|}
\hline \multicolumn{3}{|c|}{ ASHRAE 55} & \multicolumn{3}{|c|}{ ISO 7730} \\
\hline $\begin{array}{l}\text { Temp. radiante } \\
\text { - temp. ar }\left({ }^{\circ} \mathrm{C}\right)\end{array}$ & $\begin{array}{l}\text { Incremento na } \\
\text { temp. ar }\left({ }^{\circ} \mathbf{C}\right)\end{array}$ & $\begin{array}{c}\text { Vel. ar } \\
(\mathbf{m} / \mathbf{s})\end{array}$ & $\begin{array}{l}\text { Temp. } \\
\operatorname{ar}\left({ }^{\circ} \mathrm{C}\right)\end{array}$ & $\begin{array}{c}\text { Turbulência } \\
(\%)\end{array}$ & $\begin{array}{c}\text { Vel. ar } \\
(\mathbf{m} / \mathbf{s})\end{array}$ \\
\hline \multirow{3}{*}{$\operatorname{tr}-\operatorname{ta}=1$} & 1,10 & 0,30 & \multirow{3}{*}{24} & 40 & 0,20 \\
\hline & 2,20 & 0,60 & & \multirow{2}{*}{60} & 0,20 \\
\hline & 3,30 & 0,80 & & & \\
\hline \multirow{3}{*}{$\operatorname{tr}-\mathrm{ta}=0$} & 1,10 & 0,30 & \multirow{3}{*}{26} & 40 & 0,15 \\
\hline & 2,20 & 0,60 & & \multirow{2}{*}{60} & \multirow{2}{*}{0,20} \\
\hline & 3,30 & 0,80 & & & \\
\hline
\end{tabular}

Tabela 1 - Valores da velocidade do ar obtidos de acordo com as especificações da ASHRAE 55 (2004) e ISO 7730 (2005) 


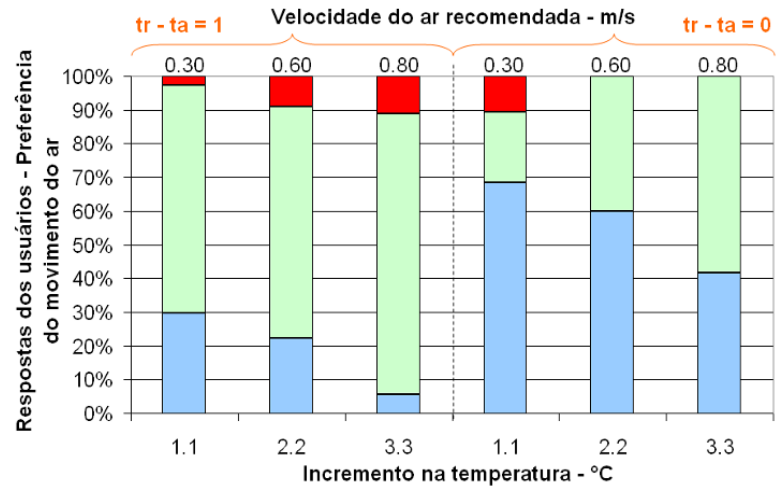

(a)

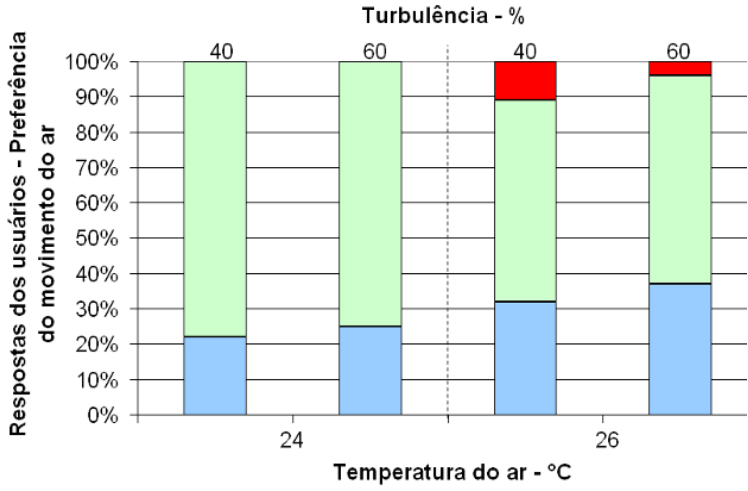

(b)

Legenda:

$\square$ Maior movimento do ar $\square$ Assim mesmo $\square$ Menor movimento do ar

Figura 3 - Gráfico da preferência do movimento do ar tendo como referência as especificações da ASHRAE 55 (b) e ISO 7730 (a)

\begin{tabular}{c|c|c|c|c}
\hline Inaceitável & \multicolumn{3}{|c|}{ Aceitável } & Inaceitável \\
\hline $\begin{array}{c}\text { devido à baixa } \\
\text { velocidade do ar }\end{array}$ & $\begin{array}{c}\text { mas com baixa } \\
\text { velocidade do ar }\end{array}$ & $\begin{array}{c}\text { velocidade do ar } \\
\text { suficiente }\end{array}$ & $\begin{array}{c}\text { mas com alta } \\
\text { velocidade do ar }\end{array}$ & $\begin{array}{c}\text { devido à alta } \\
\text { velocidade do ar }\end{array}$ \\
\hline
\end{tabular}

Tabela 2 - Escala para a aceitabilidade do movimento de ar

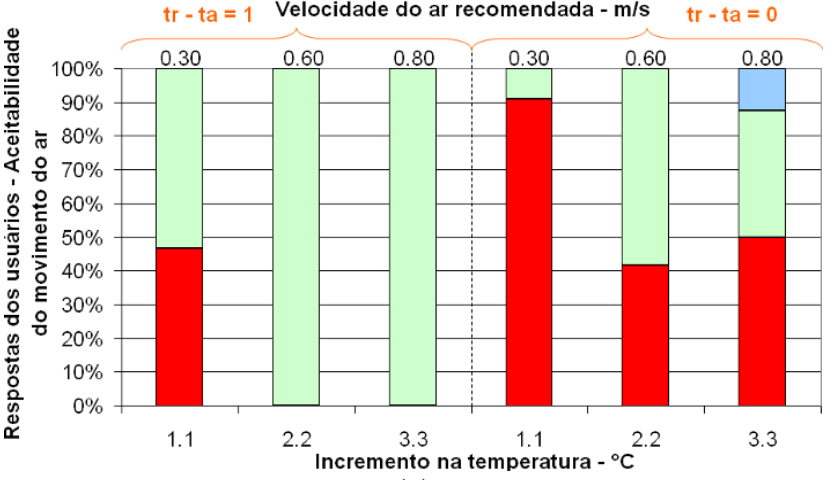

(a)

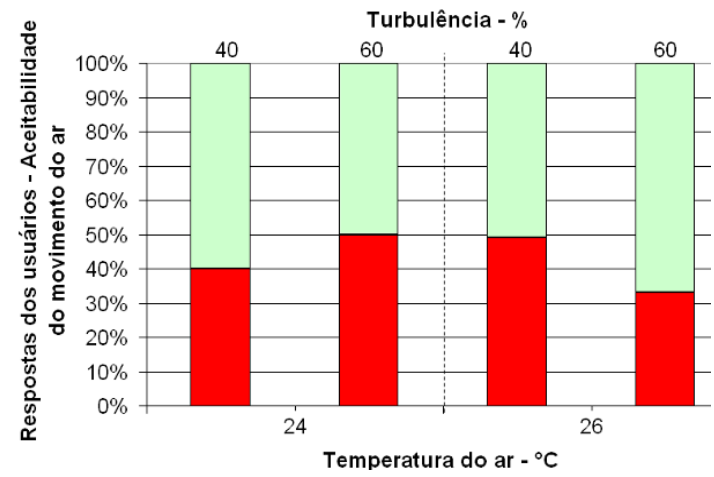

(b)

Legenda:

$\square$ Baixa velocidade do ar $\square$ Velocidade do ar suficiente $\square$ Alta velocidade do ar

Figura 4 - Gráfico da aceitabilidade do movimento do ar tendo como referência as especificações da (a) ASHRAE 55 e (b) ISO 7730

\section{Aceitabilidade do movimento do ar}

Ao se combinar a análise de preferência com a aceitabilidade do movimento de ar, os resultados são ainda mais expressivos. Os usuários entrevistados podiam classificar o movimento do ar como aceitável ou inaceitável e depois fornecer informações específicas sobre a velocidade do ar. As respostas foram agrupadas em uma escala que varia entre aceitável e inaceitável, e que pode ser vista na Tabela 2. Para esta análise, consideraramse as três respostas dos usuários para o movimento do ar aceitável, visto que não foram registrados votos para as duas categorias de inaceitável nas faixas limítrofes para a temperatura e turbulência utilizadas por ambas as normas

As Figuras 4a e 4b sumarizam os resultados para as três diferentes respostas dos usuários que consideraram a velocidade do ar aceitável. Assim como para a preferência do movimento do ar, os resultados foram separados em duas categorias, dependendo do valor resultante da diferença entre a temperatura radiante e a do ar. Quando essa diferença foi de $1{ }^{\circ} \mathrm{C}$ e a velocidade do ar de 0,30 $\mathrm{m} / \mathrm{s}, 47 \%$ dos usuários classificaram o movimento como "aceitável, mas com baixa velocidade do ar", e os $53 \%$ restantes indicaram movimento do ar "aceitável, com velocidade suficiente". Nas duas 
demais faixas de velocidade do ar, de $0,60 \mathrm{~m} / \mathrm{s}$ e de $0,80 \mathrm{~m} / \mathrm{s}$, as respostas foram para "velocidade do ar suficiente". Em nenhuma das faixas de velocidade os usuários indicaram movimento do ar "aceitável, mas com alta velocidade".

Quando a diferença entre a temperatura radiante e a temperatura do ar foi nula, aproximadamente 90\% dos usuários responderam "aceitável, mas com baixa velocidade do ar" para a velocidade de $0,30 \mathrm{~m} / \mathrm{s}$. Com o incremento da velocidade do ar para $0,60 \mathrm{~m} / \mathrm{s}$ e $0,80 \mathrm{~m} / \mathrm{s}$, o percentual de usuários indicando tal resposta diminuiu para $42 \%$ e $50 \%$ respectivamente. Nota-se que para velocidades de $0,80 \mathrm{~m} / \mathrm{s}$ apenas $11 \%$ dos usuários indicaram movimento do ar "aceitável, mas com alta velocidade do ar".

Utilizando o gráfico da ISO 7730 como referência, os valores para a aceitabilidade foram no mínimo de $32 \%$ e no máximo de $50 \%$ para respostas de "movimento do ar aceitável, mas com baixa velocidade do ar". O restante das respostas foi para movimento do ar "aceitável e velocidade do ar suficiente", e não houve registro de respostas para movimento do ar "aceitável, mas com alta velocidade do ar".

\section{Aplicabilidade de limites mínimos para a velocidade do ar}

Com base em análise Probit, valores mínimos da velocidade do ar foram encontrados, focando-se em $80 \%$ e $90 \%$ de aceitabilidade do movimento do ar. O gráfico da Figura 5 sumariza os valores encontrados para velocidades máximas de acordo com a ISO 7730, ASHRAE 44 e Arens et al. (2009), e comparação com os valores mínimos para aceitabilidade do movimento do ar de $80 \%$ e $90 \%$

A Figura 5 mostra que a velocidade mínima necessária para atingir $80 \%$ e $90 \%$ de aceitabilidade do movimento do ar é superior aos valores especificados pelas normas ASHRAE 55 e ISO 7730, em comparação com os valores indicados pelo estudo de Arens et al. (2009). Notase que os valores mínimos encontram-se na área onde o controle local não é necessário e entre o limite inferior e o superior dessa zona. Em termos de valores máximos, ocupantes consideraram 1,60 $\mathrm{m} / \mathrm{s}$ ainda aceitável, e valores similares a este foram encontrados por Tanabe e Kimura (1987) em câmaras climáticas no Japão. $\mathrm{O}$ valor de 1,60 $\mathrm{m} / \mathrm{s}$ é acima da linha limítrofe de $1,20 \mathrm{~m} / \mathrm{s}$, em que o controle local começa a ser necessário (a cada 6 ocupantes) por Arens et al. (2009).

Tais resultados sugerem que a utilização de valores mínimos se constitui em diferente abordagem e difere da utilizada em normas, cuja preocupação está voltada para valores máximos. No entanto, quando os usuários têm acesso e controle, a inserção de valores mínimos de velocidade do ar para fins de conforto ambiental parece ser mais relevante. Outro fator é a possibilidade de acionamento de ventiladores para compensar períodos de calmaria. A Figura 6 sumariza resultados para o uso de ventiladores distribuídos por temperaturas operativas. Nos ambientes aqui estudados, o controle das janelas e, principalmente, o acionamento dos ventiladores ocorreram em grupo, média de 1 ventilador para aproximadamente cada 6 ocupantes, número este similar à recomendação de Arens et al. (2009) para o chamado controle local.

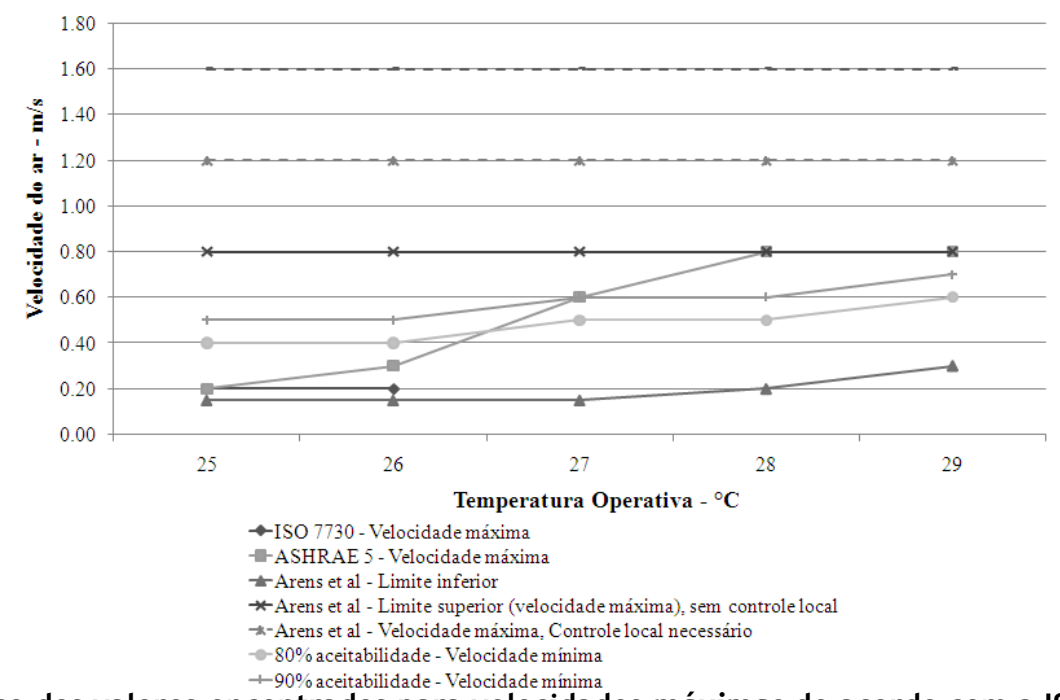

Figura 5 - Gráfico dos valores encontrados para velocidades máximas de acordo com a ISO 7730, ASHRAE 44 e Arens et al. (2009) e comparação com os valores mínimos para aceitabilidade do movimento do ar de $80 \%$ e $90 \%$ 


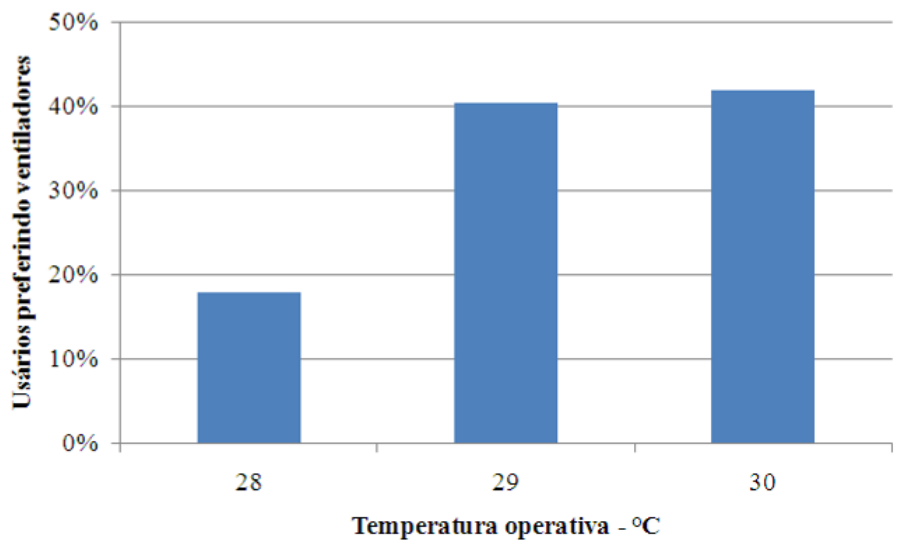

Figura 6 - Preferência de ventiladores para temperaturas operativas acima de $28^{\circ} \mathrm{C}$

A Figura 5 mostra a preferência por ventiladores para valores de temperatura operativa acima de 28 ${ }^{\circ} \mathrm{C}$. É possível notar que o número de ocupantes que demandam por ventiladores aumenta de acordo com o incremento da temperatura operativa, indicando a preferência dessa oportunidade adaptativa para restabelecer o conforto térmico. No entanto, estudos anteriores ressaltam uma relação direta entre o histórico de exposição prévia dos ocupantes (CHUN et al., 2008) e a preferência pelo uso de ventiladores e de ambientes naturalmente ventilados (OLESEN, 2004), revelando uma espécie de "vício". Quanto mais expostos a ambientes condicionados naturalmente, ocupantes tendem a preferir ventilação natural e ventiladores. Por sua vez, quanto mais expostos a ambientes com arcondicionado, mais os ocupantes preferem esse tipo de condicionamento (CÂNNDIDO et al., 2010).

\section{Sugestões de indicadores para normas brasileiras}

Utilizando os dados aqui apresentados, os seguintes itens são sugeridos para normas brasileiras:

(a) capacidade adaptativa ${ }^{3}$;

(b) o conceito de capacidade adaptativa engloba desde a preocupação com a orientação do sítio até o controle local dos usuários. A adoção de oportunidades adaptativas demonstrou ser de grande utilidade para incrementar o movimento do ar para fins de conforto térmico. As edificações aqui investigadas oferecem grande porosidade ao fluxo de ar e dispositivos complementares para a ventilação (ventiladores de teto), além de flexibilidade do vestuário e controle/acesso dos dispositivos de incremento da ventilação (janelas e

\footnotetext{
${ }^{3}$ Termo livremente traduzido de "adaptive capacity" (KWONG;
} RAJKOVICH, 2010). ventiladores). Tais itens, quando combinados, parecem contribuir para o restabelecimento do conforto dos usuários e para a aceitabilidade de velocidades mais elevadas;

(c) limites mínimos de velocidade do ar;

(d) a adoção de valores mínimos, ao invés de máximos, parece ser uma mudança de enfoque necessária para o contexto climático aqui investigado. Os limites mínimos encontrados visaram estabelecer $80 \%$ e $90 \%$ de aceitabilidade do movimento do ar e ficaram claramente acima dos estabelecidos por normas internacionais. Valores acima de $0,80 \mathrm{~m} / \mathrm{s}$ e até $1,60 \mathrm{~m} / \mathrm{s}$ foram aceitos pelos usuários e, por sua vez, deveriam ser adotados em climas quentes e úmidos. A aplicabilidade dos limites mínimos aqui encontrados, no entanto, necessitam ser comparados com outros experimentos de campo em contextos climáticos diferenciados;

(e) adoção de ventiladores como dispositivos complementares da velocidade do ar; e

(f) a preferência pela adoção de ventiladores foi clara acima de temperatura operativa de $28^{\circ} \mathrm{C}$, e aqui, mais uma vez, os usuários fizeram uso dessa oportunidade adaptativa.

O uso de ventiladores pode ser bastante útil para incrementar a velocidade mínima necessária para o conforto dos usuários, principalmente em períodos de calmaria. Requerimentos específicos podem ser identificados, especialmente no que concerne ao controle dos usuários.

\section{Conclusões}

Este artigo teve como objetivo investigar a aplicabilidade dos limites dados para a velocidade do ar pelas normas ASHRAE 55 (2004) e ISO 7730 (2005) com os resultados de preferência e aceitabilidade do movimento do ar obtidos em 
experimentos de campo no clima quente e úmido de Maceió/AL.

Resultados indicam que ambas as normas especificam valores para a velocidade do ar inferiores aos desejados pelos usuários dos ambientes aqui investigados. Os resultados para a preferência do movimento do ar indicam que significativa percentagem dos usuários demanda "maior movimento do ar", sendo os valores para "menor velocidade do ar" bastante inferiores. Quando associada às respostas da aceitabilidade do movimento do ar, a insatisfação dos usuários ficou mais evidente, indicando a demanda por "maior velocidade do ar". Os limites estabelecidos pelas normas tendem a superestimar a insatisfação dos usuários pelo incremento do movimento do ar. Os usuários, por sua vez, aceitam e preferem valores de velocidade do ar mais elevados como forma de restabelecimento do conforto térmico.

Do ponto de vista da percepção e expectativa, os conceitos de preferência e de aceitabilidade do movimento do ar parecem estar fortemente relacionados a questões subjetivas dos usuários, principalmente à adaptação às flutuações de tais valores, assim como ocorre para a temperatura do ar. O estímulo causado pelas flutuações do movimento do ar parece ser desejado pelo usuário por questões subjetivas e essencialmente individuais. Os valores máximos dados pelas normas aqui utilizadas como referência não contemplam tais questões, permitindo maiores percentuais de insatisfação pelo movimento do ar insuficiente, e não o excessivo. Já do ponto de vista fisiológico, o incremento do movimento do ar demandado pelos usuários pode ser associado ao estímulo ou alliesthesia positiva, auxiliando no restabelecimento do conforto do usuário (DEAR, 2009). As flutuações do movimento e velocidade do ar, quando associadas à temperatura, podem ser não só bem-aceitas como também desejadas pelos usuários.

Outro ponto de relevância identificado foi a importância de dispositivos complementares para o incremento do movimento do ar. A preferência pelo uso de ventiladores foi significativa para temperaturas acima de $28{ }^{\circ} \mathrm{C}$ e indica o uso de oportunidades adaptativas pelos usuários. É importante destacar que os usuários possuíam o controle dos mecanismos de incremento do movimento do ar, tais como janelas e ventiladores, sendo este um item de essencial importância no processo de intensificação do movimento do ar nos ambientes.

Por fim, três itens foram sugeridos como indicadores para normas brasileiras: capacidade adaptativa, limites mínimos para a velocidade do ar e adoção de ventiladores. No entanto, mais experimentos de campos são indubitavelmente necessários visando a um maior entendimento da aplicabilidade e das limitações dos valores aqui encontrados em diferentes contextos climáticos. Os dados apresentados neste trabalho indicam que draft não parece ser um risco, nem, portanto, uma limitação, para o incremento do movimento do ar nos ambientes investigados.

\section{Referências}

ARENS, E. A. et al. A Study of Occupant Cooling by Personally Controlled Air Movement. Energy and Buildings, v. 27, n. 1, p. 45-59, 1998.

ARENS, E. et al. Moving Air for Comfort. ASHRAE Journal, p. 18-29, 2009.

ASHRAE. Standard 55: thermal environmental conditions for human occupancy. ASHRAE: Atlanta, 2004.

CABANAC, M. Physiological Role of Pleasure. Science, v.17, p. 1103-1007, 1971

CÂNDIDO, C. et al. Cooling Exposure in Hot Humid Climates: are occupants "addicted"? Architectural Science Review, v. 53, n. 1, p. 59 64, 2010.

CHUN, C. et al. Thermal Diary: connecting temperature history to indoor comfort. Building and Environment, v. 43, n. 5, p.877-885, maio 2008.

DEAR, R. de. The Theory of Thermal Comfort in Naturally Ventilated Indoor Environments: "The pleasure concept". In: INTERNATIONAL WORKSHOP ON NATURAL VENTILATION, 3.,Tokyo, 2009. Proceedings... Tokyo, 2009.

DEAR, R. de; BRAGER, G. Thermal Comfort in Naturally Ventilated Buildings: revisions to ASHRAE Standard 55. Energy and Buildings, v. 34 , n. 6, p. 549-563, 2002.

FANGER, P. O.; PEDERSEN, C. J. K. Discomfort Due to Air Velocities in Spaces, Proc. of Meeting of Commission B1, B2, E.1 of Int. Instit. Refrig., 289- 296, 1977. 4 p.

FANGER, P. O., CHRISTENSEN, N. K. Perception of Draught in Ventilated Spaces, Ergonomics, v. 29, n. 2, p. 215-235, 1986. 
INTERNATIONAL ORGANIZATION FOR STANDARD. ISO 7730: moderate thermal environments: determination of the PMV and PPD Indices and Specification of the conditions of Thermal Comfort. Geneva, 2005.

MCINTYRE, D. A. Preferred Air Speed for Comfort in Warm Conditions. ASHRAE Trans, v. 84, n. 2, p. 264-277, 1978.

OLESEN, B.W. International Standards for the Indoor Environment. Indoor Air, v. 14, supplement 7, p. 18-26, 2004.

TANABE, S.; KIMURA, K. Thermal Comfort Requirements Under Hot and Humid Conditions. In: ASHRAE FAR EAST CONFERENCE ON AIR CONDITIONING IN HOT CLIMATES, Singapore. Proceedings... Singapore: ASHRAE, 1987. p. 3-21.
YANG, W.; ZHANG, G. Thermal Comfort in Naturally Ventilated and Air-Conditioned Buildings in Humid Subtropical Climate Zone in China. International Journal of Biometeorology, v. 52, n. 5, p. 385-398, 2008.

ZHANG, G. et al. Thermal Comfort Investigation of Naturally Ventilated Classrooms in a Subtropical Region. Indoor and Built Environment, v. 16, p. 148-158, 2007a.

ZHANG, H. et al. Air Movement Preferences Observed in Office Buildings. International Journal of Biometeorology, v. 51, p. 349-360, 2007b. 